\author{
Military Technical College \\ Kobry Elkobbah, Cairo, \\ Egypt.
}

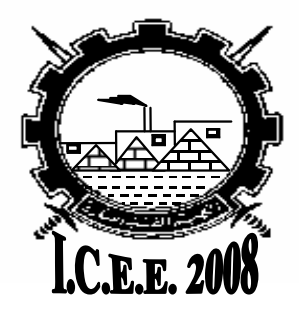

$4^{\text {th }}$ International Conference On Chemical \& Environmental Engineering 27-29 May 2008

\title{
TEXTILE FABRIC TREATMENT AGAINST RADAR DETECTION USING GRAPHITE
}

\author{
Fayed M. S*. , Allam A.M*., Mostafa S. F* , Ramzy* H. $^{*}$
}

\begin{abstract}
The reduction of radar signature by textile fabric treated with graphite powder suspended in shellac solution is investigated. In this study, graphite was added with known concentration in shellac solution and mixed until homogeneity. The prepared textile fabric was treated with solution of graphite and tested by microwave reflectometer to measure the reduction in reflected radar power and also the reduction of radar signature. The results of these measurements were recorded.
\end{abstract}

\section{KEY WORDS}

Radar signature; textile fabric; graphite; shellac solution; microwave reflectometer; reflected radar power. 


\section{INTRODUCTION}

Stealth is the art of concealing targets from detectors by reduction of signature. The threat of radar detection is usually a major concern to an attacking force and a lot of effort was put into trying to reduce radar signature [1]. The stealth technology aims to the design and proposal of materials and techniques that can lead to the reduction of the target signature in the infrared, visible, acoustic and radar domains [2]. Radar cross section(RCS) is a measure of reflective strength of target. Also it is defined as the projected area of a metal sphere which would return the same echo signal as the target had [3-5]. The methods of radar cross section reduction(RCSR) are Shaping, radar absorbing materials, passive cancellation and active cancellation. Although shaping has an important role in radar cross section reduction and can provide reduction in signature over limited aspect angles, many situations require absorption of the incident electromagnetic energy. Radar absorbing materials are based on the fact that some substances absorb energy from electromagnetic field passing through it $[5,6]$. The material ability to store energy was characterized by defining two parameters, Permittivity $(\Theta)$ that characterizes materials ability to store electrical energy and Permeability $(\mu)$ that characterizes materials ability to store magnetic energy. The loss refers to the dispersion of power or energy [7]. The radar absorber measurement techniques are RCSmethod, the naval research laboratory (NRL) arch method and large waveguide system [8-10]. In this work the technique of radar absorbing material as one of the simplest ways to reduce the returned radar signal power from the object was applied. graphite is used with as magnetic absorbing materials which applied in anechoic chambers [11]. The reduction of radar signature for the treated textile fabric with graphite suspended in shellac solution was investigated.

\section{EXPERIMENTAL WORK}

\subsection{Experimental Set-up}

The PR-17 microwave reflectometer is portable, swept frequency reflectance analyzer used for the testing of the microwave reflectivity of surface. It operates in free space using transmit and receive antennas oriented at a \pm 15 degree bistatic angle compared with the surface normal to measure relative return loss. The reflectometer gun as shown in figure (1) contains internal computer to control system operations and displays and stores the measured data. Also the transmit and receive antennas which send and receive the electromagnetic wave and record the reduction in reflected radar power.

\subsection{Textile Fabric Specifications}

The textile fabrics were chosen from the commercially available ones with known specifications and characterization. All these textile fabrics were obtained Before dyeing and without any further treatment. The selected samples of different types were cut into specimens of known dimensions $30 \times 30 \mathrm{~cm}$, which is the suitable size for testing. The specimens were weighed before treatment and testing. The type of textile fabrics used was cotton $100 \%$ ( plain weave) and mixed (cotton $40 \%$ and polyester $60 \%$ ) of satin weave. 


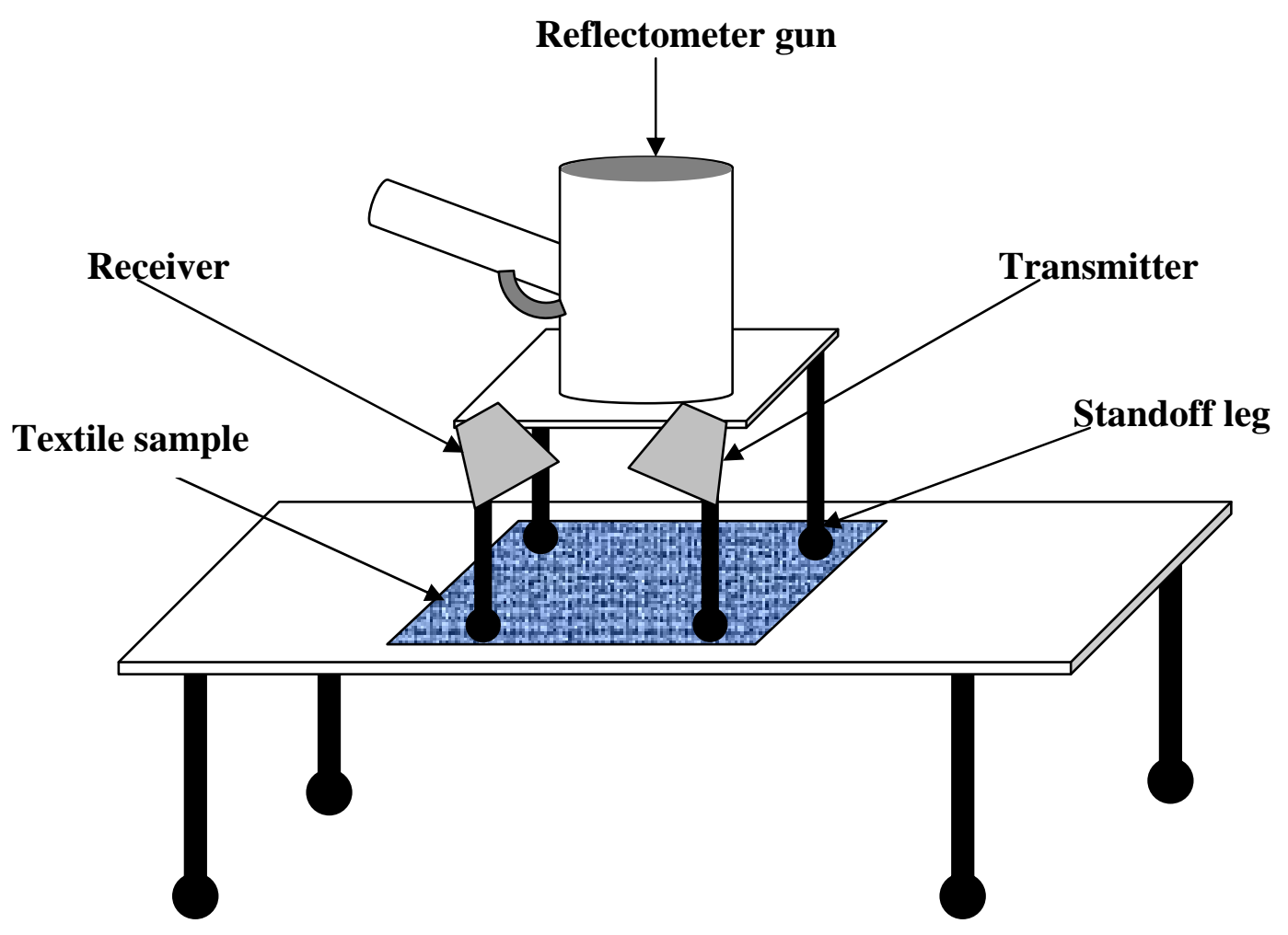

Fig.1. Experimental set-up used for testing the textile sample by microwave reflectometer

Table 1 Textile fabric specifications

\begin{tabular}{|c|c|c|c|c|c|c|c|c|}
\hline \multirow{2}{*}{ No. } & \multicolumn{9}{|c|}{ Fabric type } \\
\cline { 2 - 9 } & Structure & Raw material & $\begin{array}{c}\text { Weight } \\
\left(\mathrm{g} / \mathrm{m}^{2}\right)\end{array}$ & Count & No./cm & $\begin{array}{c}\text { Thickness } \\
(\mathrm{mm})\end{array}$ & \multicolumn{2}{|c|}{ Strength (kg) } \\
\cline { 5 - 9 } & $\begin{array}{c}\text { Width } \\
\text { Plain } \\
\text { weave } \\
\text { (Gercie) }\end{array}$ & $100 \%$ Cottongth & 240 & 24 & $9 \times 16$ & 0.96 & 40.6 & 21.7 \\
\hline 2 & $\begin{array}{c}\text { Satin } \\
\text { weave } \\
\text { (Rib) }\end{array}$ & $\begin{array}{c}\text { Mixed (Cotton } \\
40 \%, \text { Polyester } \\
60 \%)\end{array}$ & 270 & 20 & $10 \times 17$ & 0.94 & 40.9 & 23.1 \\
\hline
\end{tabular}

Where:

Count: number of fibrles per one inch.

Weight: weight of sample per meter square.

No./cm: number of fibrles per $\mathrm{cm}$ in both width and length directions. 


\subsection{Preparation of Chemical Solution}

\subsubsection{Alcoholic shellac alcoholic solution}

The mentioned natural polymer(100g) was dissolved in pure ethanol(500ml) and thoroughly mixed until complete dissolution of shellac to form a dark brown true solution, then $200 \mathrm{~g}$ of this prepared solution is weighed and then different amount of graphite with particle size ranged between $10-20 \mu \mathrm{m}(20,30,40$ and $50 \mathrm{~g})$ were separately added to the prepared solution and thoroughly mixed. The textile samples were soaked in this solution for $5 \mathrm{~min}$, dried and weighed. These procedures repeated several times until constant weight of the sample. The drying process was done in oven at $50^{\circ} \mathrm{C}$ for 3 hours.

\subsubsection{Commercial epoxy resin}

The ratio of the resin to hardener is $5: 1$. The graphite amount is added to the thoroughly mixed epoxy resin $(200 \mathrm{~g})$ and mixed till homogeneity. Four samples were prepared with different amount of graphite 20,30, 40 and $50 \mathrm{~g}$.The mixture is totally used to coat the sample. The solution was saturated after adding $50 \mathrm{~g}$ of graphites that the last sample was treated with solution containing this amount of graphites. The thickness and weight of the coated samples were measured after curing in oven at $50{ }^{\circ} \mathrm{C}$ for 3 hours. The treated samples were then tested as radar absorbent. The factors affecting the reduction of radar signature were: Effect of concentration of chemical compound in solution formula, Effect of varying wavelength along the frequency band and effect of textile fabric type.

\section{RESULTS AND DISCUSSIONS}

\subsection{Effect of graphite percentage on reduction of reflected radar power}

After treatmet of textile fabric with a formulation containing variable percentage of graphite, the results of measurements were illustrated in table 2.

Referring to the results in table 2. there is a gradual decrease in the reduction of the reflected radar power with the increase in the wavelength. The greatest effect was traced to be at $18 \mathrm{GHz}$ for each sample. For example sample $\mathrm{G} 1$ the reduction at 18 $\mathrm{GHz}$ is about 2.5 times that at $8 \mathrm{GHz}$. There is an appreciable increases in the reduction of reflected power as the percentage of graphite increases at each wavelength in all the tested samples G1,G2,G3 and G4 
Table 2. Reflected power of $100 \%$ cotton textile fabric treated with different concentration of graphite in shellac suspended in ethanol.

\begin{tabular}{|c|c|c|c|c|c|}
\hline \multicolumn{2}{|c|}{ Sample Code } & G1 & G2 & G3 & G4 \\
\hline \multicolumn{2}{|c|}{ Fabric Type } & \multicolumn{4}{|c|}{ Cotton $100 \%$ plain weave } \\
\hline \multicolumn{2}{|c|}{$\begin{array}{c}\text { Sample weight } \\
(\mathrm{g} / \mathrm{m} 2)\end{array}$} & 415 & 438 & 456 & 474 \\
\hline \multicolumn{2}{|c|}{$\begin{array}{c}\text { Graphite Concentration } \\
(\%) \\
\end{array}$} & $9 \%$ & $13 \%$ & $17 \%$ & $20 \%$ \\
\hline \multicolumn{2}{|c|}{\begin{tabular}{|c|}
$\begin{array}{c}\text { Sample thickness } \\
(\mathrm{mm})\end{array}$ \\
\end{tabular}} & 1.01 & 1.03 & 1.04 & 1.06 \\
\hline & & \multicolumn{4}{|c|}{ Reduction in RCS at frequency band $8-18 \mathrm{GHz}(\mathrm{dB})$} \\
\hline \multirow{11}{*}{ 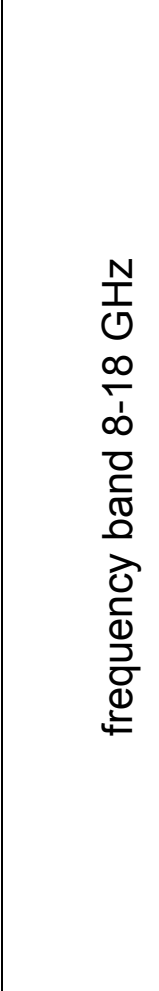 } & 8 & -4.2133 & -5.0231 & -7.5261 & -9.2062 \\
\hline & 9 & -4.5166 & -5.3167 & -7.7321 & -9.1339 \\
\hline & 10 & -4.2135 & -5.0250 & -7.5982 & -9.0616 \\
\hline & 11 & -3.9216 & -4.9439 & -7.4426 & -8.9637 \\
\hline & 12 & -3.5324 & -4.8600 & -7.3168 & -8.9106 \\
\hline & 13 & -3.3511 & -4.6761 & -7.2536 & -8.7674 \\
\hline & 14 & -2.9477 & -4.5335 & -7.0131 & -8.5776 \\
\hline & 15 & -2.5235 & -4.4696 & -6.9536 & -8.4928 \\
\hline & 16 & -2.3151 & -4.3699 & -6.8417 & -8.4438 \\
\hline & 17 & -2.1497 & -4.2762 & -6.7322 & -8.4193 \\
\hline & 18 & -1.9842 & -4.1825 & -6.5314 & -8.4038 \\
\hline
\end{tabular}




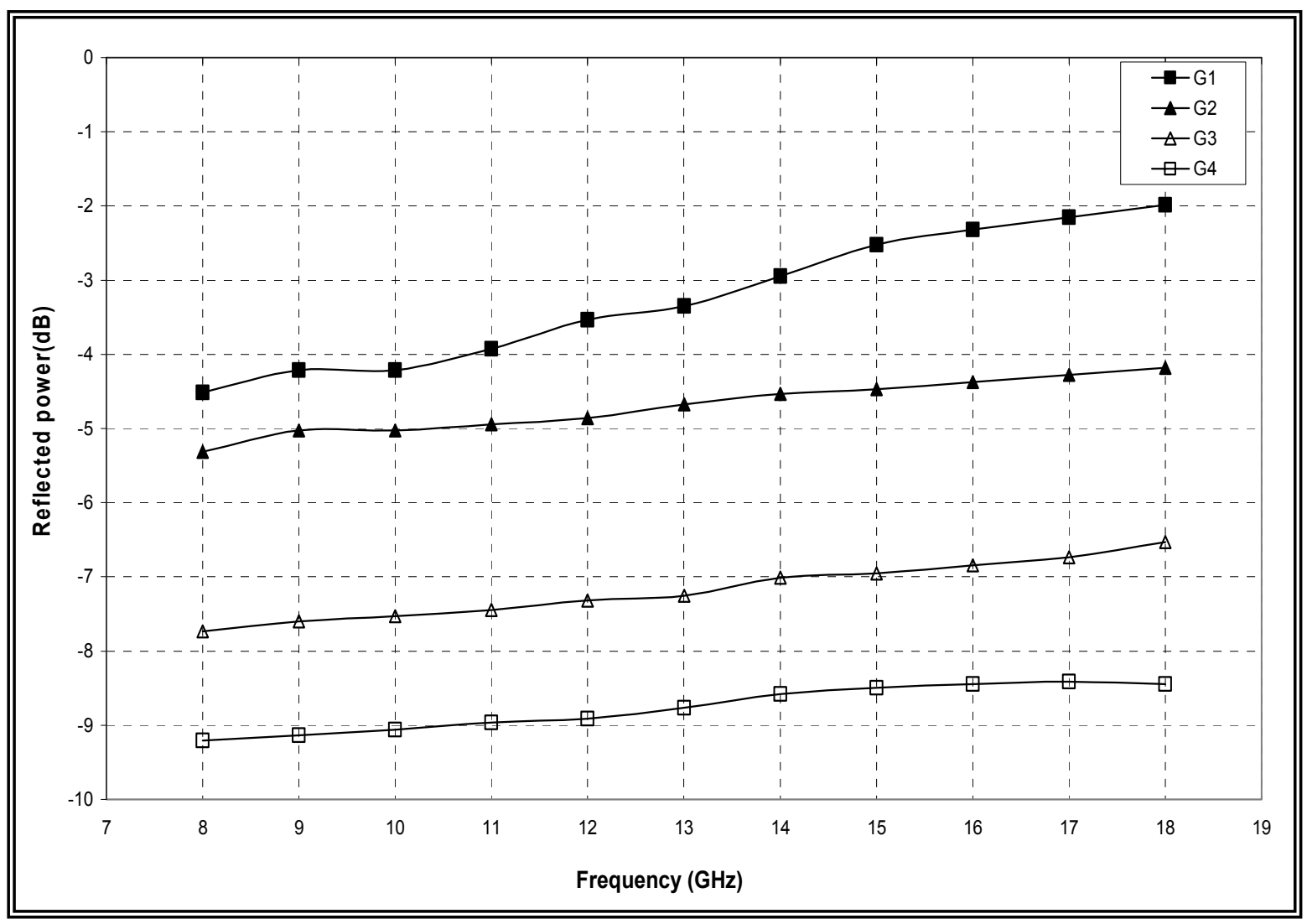

Fig.2. Relation between the frequency and reflected power of $100 \%$ cotton textile fabric with different concentration of graphite in alcoholic shellac solution.

Fig.2. illustrates that, For treated graphite samples, the reduction in reflected radar power decrease with the increase of wavelength along the frequency band.

\subsection{Effect of polymer binder on reduction of reflected radar power}

After treatment of $100 \%$ cotton textile fabric with different concentrations of graphite in commercially available epoxy polymer, the results of measurements were illustrated in fig.3.The same trend explained with the natural shellac was observed with a very slight variation in the corresponding reading. 


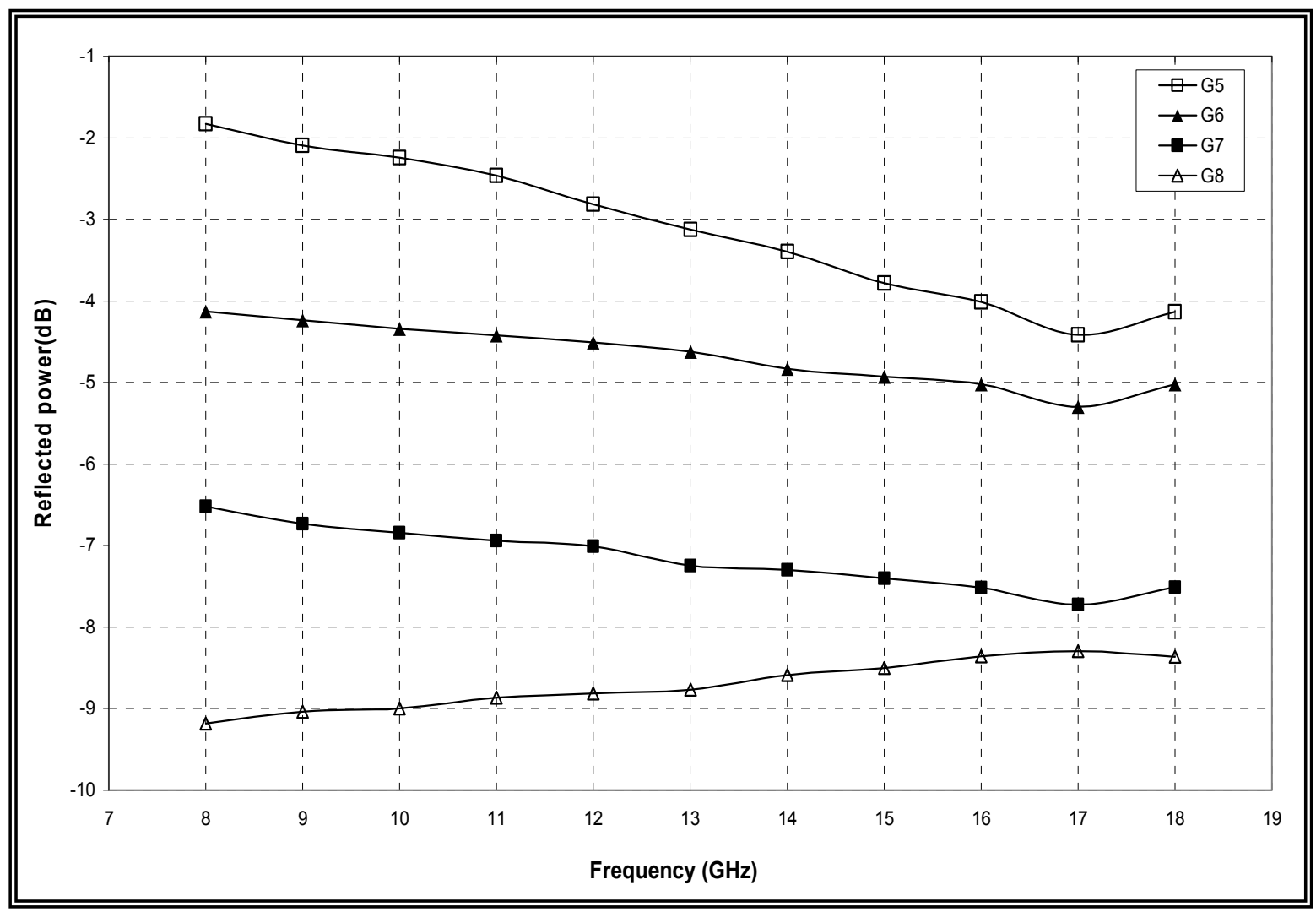

Fig.3. Relation between the frequency and reflected power of $100 \%$ cotton textile fabric with different concentration of graphite in epoxy polymer.

As shown in fig.3., we found that the best tested sample was that of $G 8$ as that of $G 4$ indicating that the binder has no remarked effect of the technological specification of the samples. The remarked small difference can be attributed to the method of treatment where in case of shellac solution there is a better diffusion of graphite inside the fiber structure where it is of little extent in case of coating. The results in fig.3. illustrates also that for every curve of the tested samples $(G 5, G 6, G 7, G 8)$ the reduction in RCS decrease as the wavelength increase.

\subsection{Effect of fabric type on reduction of reflected radar power}

In the same way the blend textile fabric (40\%cotton, $60 \%$ polyester) was tested with graphite to investigate its behavior in the effect and treatment. The results of measurements were illustrated in fig.4. 


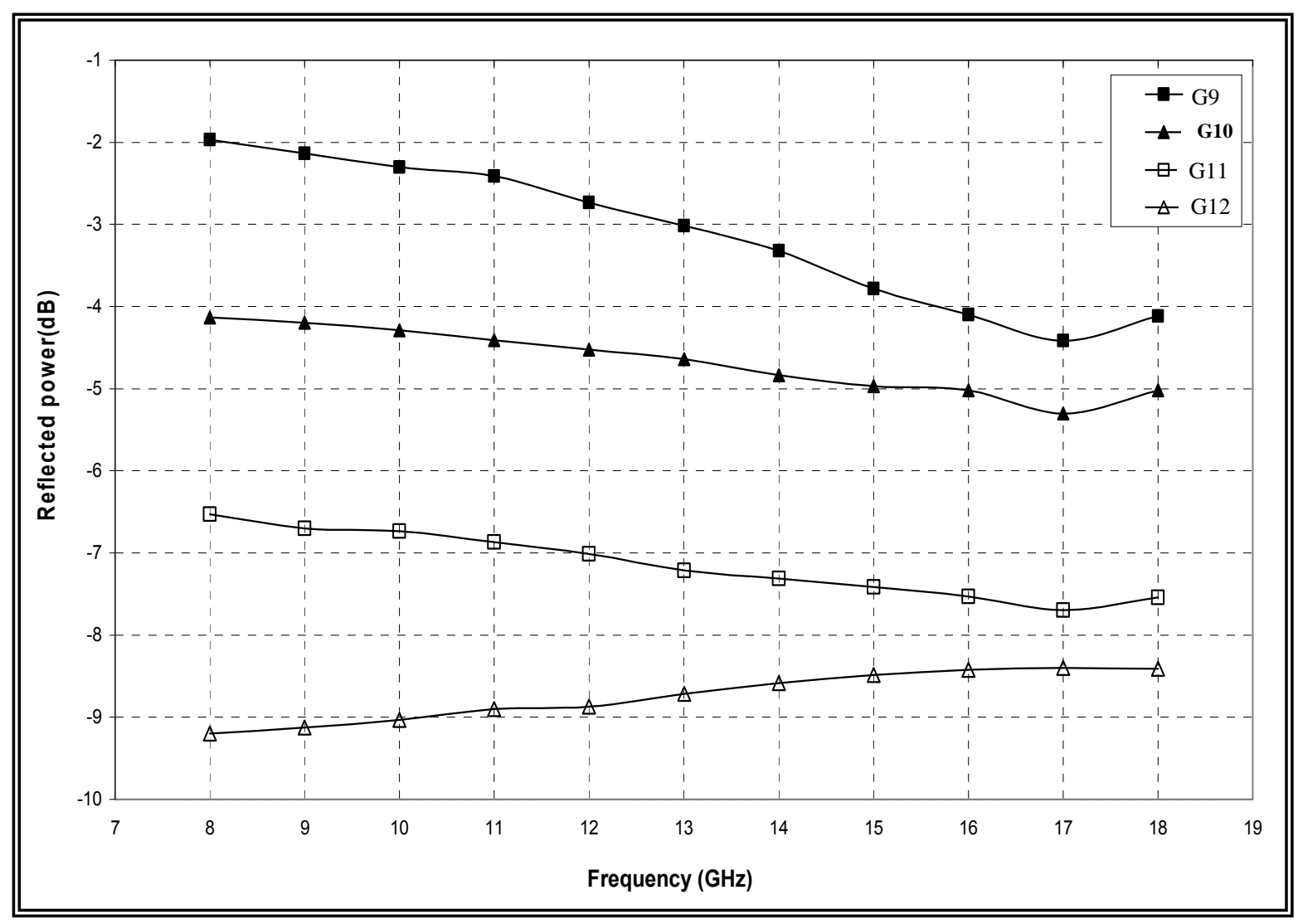

Fig.4. Relation between the frequency and reflected power of cotton-polyester (40\%$60 \%$ ) textile fabric with different concentration of graphite in shellac solution

The results indicated that there is no change in results when we use mixed cotton $40 \%$ and polyester $60 \%$, but when we use textile fabrics with low fabric weight and small thickness for yarn count, the quality of absorbed graphite through the surface of the used fabric decrease. Generally we found that as concentration of graphite in shellac dissolved in ethanol increase the reduction in RCS increase as for sample G12.

\section{CONCLUSION}

The most commonly used material in field applications is graphite since it is nonmetallic and non-conducting material so it was selected to be tested for such purpose to study its effect and the different factors that can influence such purpose. It is also well known that each radar absorbing material absorbs certain radar wavelength better than the others. Therefore, the aim of such work is also to determine the suitable absorbers wavelengths and so for the proposed field applications. From the experimental work done and the tested samples, it was found that The textile fabrics 
were chosen to be $100 \%$ cotton and mixed cotton (40\%) and polyester( $60 \%$ ) or coating of textile fabric in case of using commercial epoxy resin .

The method of treatment were soaking of mixtures in shellac polymer, as the concentration of the chemical compound in solution formula increases, the reduction in reflected radar power increases. For graphite, the sample G4 with $100 \%$ cotton textile fabric treated with shellac in ethanol was better in the range $14-18 \mathrm{GHz}$. The same was also obtained with blend textile fabric. The reduction in radar power was in the range of -10.027 to $-11.194 \mathrm{~dB}$.

The textile samples have less thickness and they were more flexible and can be used in different applications like manufacture of tents and covers of army vehicles or can be used to camouflage the fixed objects.

\section{REFERENCES}

[1] W.F.Bahret, "The Beginning of Stealth Technology", IEEE Trans. Aerospace Electron system, USA, 1998.

[2] David K.Barton, Sergy A.Leonvov, "Radar Technology Encyclopedia ", Artech house, Boston, London, 1970.

[3] Merrill I.Skolnik, "Radar Hand book", Second Edition, New York, 1972.

[4] Jay, F., IEEE standard dictionary of electrical and electronics term.1995.

[5] Eli Brookner, "Radar Technology", Second Edition, Raytheon Company, Wayland,

[6] Eugene F.Knott, John F.Shaeffer, Micheal T.Tuley "Radar Cross Section", Second Edition, Artech house, Boston, London, 1994.

[7] J.Clarke,"Advances in Radar Techniques", London, UK, 1985.

[8] J.A.Adam, "How to Design an Invisible Aircraft", IEEE spectrum, vol.25, USA, 1988.

[9] Francois, Lechevalier,"Principles of Radar and Sensor signal processing", Artech house, Boston, London, 2002.

[10] Merrill I.Skolnik, "Introduction to Radar", Third Edition, Mc Graw Hill, New York, 1991.

[11] Juhi Garg, Ashok Gupta "A Guided Tour to K.V Microwave Materials", India, 1991. 